\title{
Sample preparation using liquid membrane extraction techniques
}

\author{
Titus Msagati ${ }^{1}$, Luke Chimuka ${ }^{2 *}$ and Ewa Cukrowska ${ }^{2}$ \\ ${ }^{1}$ University of KwaZulu-Natal, School of Chemistry, Private Bag X54001 Westville Campus, Durban 4000, South Africa \\ ${ }^{2}$ School of Chemistry, University of the Witwatersrand, P/Bag 3, WITS 2050, Jorissen Street, Braamfontein, \\ Johannesburg, South Africa
}

\begin{abstract}
A brief review is given of membrane extraction techniques that are seen as suitable for the extraction of various chemicals in water samples. Membrane-based extraction methods have now gained popularity as methods of choice in the extraction of both ionisable and non-ionisable molecules from different samples. The main attractive features for these techniques include the use of minimal organic solvents, high selectivity and clean-up efficiency, with high enrichment factors. In most cases the overall cost involved is low due to the simplicity of the techniques which normally involve relatively fewer steps and handling procedures as compared to many other sample-preparation techniques. The various forms and the configurations of membrane-based techniques are another attractive feature which allows the possibility of hyphenation with separation instruments such as gas/liquid chromatographs and even capillary electrophoresis.
\end{abstract}

Keywords: liquid membrane extraction techniques, sample preparation, water monitoring, organic and inorganic compounds

\section{Introduction}

Sample preparation is among the most important steps in any analytical process. This is due to the fact that sample preparation plays an important role in the removal of macromolecules and other matrix constituents that may adversely interfere with the detection system. In addition to that, sample-preparation methods bring about a possibility of enrichment of the analytes in very dilute samples or where low detection limits are required (Jönsson, 1992; 1993; 1999). Sample-preparation processes therefore have a direct impact on accuracy, precision and quantification limits and are often a limiting step for many analytical methods (Majors, 2003). Many sample-preparation techniques (Tadeo et al., 2004; Mitra and Kebbekus, 1998; Patnaik, 1997) that have been in use all along include head space analysis, purge and trap, solid-phase micro-extraction (SPME) (Eisert et al., 1997; Pawliszyn, 2003), liquid-liquid extraction (LLE) and solid-phase extraction However, the oldest and most widely used technique is liquid-liquid extraction. The limitations of this traditional extraction technique (liquid-liquid extraction) include the lengthy extraction times, automation challenges and use of large organic solvents which are not environmentally friendly.

Recently, sample preparation employing liquid membranes has been reported in many applications, a sign that liquid membranes are a preference over many others. The use of membrane techniques for selective extraction of analyte molecules was first introduced by Audunsson who used it for the extraction of amines in urine (Audunsson, 1986) and further developed by Jönsson and Mathiasson research groups to cover a wider application to both environmental as well as biological samples (Jönsson, 1992; 1993; 1999). Membrane extraction techniques have

* To whom all correspondence should be addressed.

욜 +2711 717-6703, +27 724978041; fax: +2711 717-6749;

e-mail: luke.chimuka@wits.ac.za or luke chimuka@hotmail.com

Received 12 December 2007; accepted in revised form 20 March 2008 been used for the extraction of molecules in biological matrices (Jönsson et al., 2003; Pálmarsdóttir et al., 1997; Lindegård et al., 1992; Basheer and Lee, 2004; Msagati and Nindi, 2001; 2004a; 2004b; 2005a; 2005b; 2006; Drapala et al., 2005).

Liquid membranes have also been used extensively in the extraction of both organic molecules such as pesticides and herbicides in waters and wastewaters (Chao et al., 2002; Megersa et al., 2001; Dżygiel and Wieczorek, 2001) and metals in water and wastewater matrices (Ndungù et al., 1998; Yang and Cussler, 2000; Juang and Huang, 2000; Juang et al., 2000; 2004; Ortiz et al., 2003; Ho, 2002) as well as other organic pollutants (Berhanu et al., 2006; Khrolenko et al., 2002; Qin et al., 2002). Membranebased techniques have been coupled to a variety of other analytical instruments such as ion chromatography (Amara and Kerdjoudj 2007) liquid chromatography (Sandahl et al., 2000; 2002), gas chromatography (Luthje et al., 2004; Mitra et al, 1996), capillary electrophoresis (Palmarsdottir et al., 1997) and atomic absorption spectrophotometers (Juang et al., 2004; Fontas et al., 2005; Van de Voorde et al., 2004; Arous et al., 2004a; Arous et al., 2004b).

Generally, liquid membrane extraction techniques may be applied in many different ways, employing different types of membranes and a variety of set-ups and configurations or designs. This review discusses the different types of liquid membrane extraction techniques in their various designs.

\section{Principles of liquid membrane extraction techniques}

In liquid membrane extraction techniques, the analyte molecules diffuse across the hydrophobic porous membranes impregnated by organic solvent under a gradient which may be created due to either concentration differences $(\Delta C)$ between the two phases, the feed (or donor) and the stripping (or acceptor) or differences in the electrical potential $(\Delta E)$.

The process of diffusion in liquid membranes is governed by Fick's first law of diffusion (Smith, 2004): 


$$
\mathrm{J}=-\mathrm{D} \frac{\partial \Phi}{\partial \chi}
$$

where:

$J$ denotes the extent of flux of the analyte molecules per given area and time (e.g., g. $\mathrm{cm}^{-2} \cdot \mathrm{s}^{-1}$ or $\mathrm{mol} \cdot \mathrm{cm}^{-2} \cdot \mathrm{s}^{-1}$ )

$D$ gives the diffusibility measure of the analyte across the membrane (diffusion coefficient), with units of $\mathrm{cm}^{2} \cdot \mathrm{s}^{-1}$ and is proportional to the velocity of the diffusing particles $\Phi$ is the concentration in dimensions of amount of substance per volume e.g., $\mathrm{mol} \cdot \mathrm{cm}^{-3}$;

$\chi$ is the position e.g., $\mathrm{cm}$ or metre (m).

The concentration gradient is given by the ratio of the change in concentration $(\partial \Phi)$ to the change in position $(\partial \chi)$, that is, $\frac{\partial \Phi}{\partial \chi}$.

The term $D$ depends on the temperature, viscosity of the fluid and the size of the particles according to Stokes-Einstein equation,

$$
D=\frac{k_{B} T}{6 \pi a \eta}
$$

where:

$D$ is the diffusion constant

$A$ is the radius of solute

$\eta$ is the solution viscosity $=$ mobility of the particles

$k_{B}$ is Boltzmann's constant,

$T$ is the absolute temperature.

Integrating the Fick's equation gives Eg. (3):

$$
J=D \frac{\left(C_{i s}-C_{j l}\right)}{L}
$$

where:

$c_{i \mathrm{~s}}$ is the concentration of analyte $i$ at the outer membrane interface

$c_{i 1}$ the concentration of analyte $i$ in acceptor phase

$L$ is the membrane thickness.

From the equations above, several parameters need to be adjusted to speed up the diffusion process in order to increase the flux across the membrane. Factors which control the $D$ term (diffusion coefficient), such as temperature and partition coefficient are normally adjusted to optimal conditions for that purpose. The effect of temperature increase on the rate of diffusion and flux can be approximated by the Stokes-Einstein equation, such that by increasing $T, D$ will increase and hence the analyte's flux.

Partition coefficient $(K)$ is another important factor, which controls the diffusion (flux) of analyte molecules across the membrane. The partition coefficient is defined as the ratio of the concentration of analyte in the membrane to that in the matrix as indicated by Eq. (4):

$$
K=\frac{C_{\text {membrane }}}{C_{\text {matrix }}}
$$

where:

$C_{\text {membrane }}$ is the analyte concentration in the membrane

$C_{\text {matrix }}$ is the analyte concentration in sample matrix.

The partition coefficient plays an important role mostly in liquid membranes where analytes cross the membrane in steps, because the analyte species in the donor (feed) phase has to be dissolved first in the membrane, diffuse through passing the membrane-acceptor interface into the bulk of the acceptor phase. The analyte is thus extracted into the membrane from the donor side and then re-extracted into the acceptor phase.

\section{Typical materials used in fabricating membranes}

The types of materials used to fabricate membranes are diverse and these include polytetrafluoroethylene (PTFE), polyvinylidenefluoride (PVDF), polypropylene (mainly for hollow fibres), silicone, and polysulphone (PS) (Hylton and Mitra, 2007). These materials are known to have some qualities that give them an edge over others. The materials are known to be stable at all $\mathrm{pH}$ ranges and they are inert to many other chemicals and have high temperature stability (Hylton and Mitra, 2007).

\section{Classification of liquid membrane techniques}

Membrane techniques exist in various forms and may be classified into several groups depending on the mode of classification (Jönsson and Mathiasson, 1999). Morphologically they may be classified into porous and non-porous (though almost all liquid membrane techniques are non-porous), but geometrically they may be classified into film/flat sheet or hollow fibre configurations. In all these configurations, the analyte molecules are selectively partitioned between two or three phases. At least from the context of this review, the geometric forms of membrane techniques will be discussed.

\section{Porous membrane extraction techniques}

In actual sense these may not qualify fully as liquid membrane techniques and therefore their discussion in this review will be brief. In porous membrane techniques, the analyte molecules are partitioned from one phase which forms the feed (upstream phase) through the porous hydrophobic liquid membrane to the second phase which forms the stripping/acceptor (downstream phase) (Fig. 1) (Jonsson and Mathiasson, 2001).

The driving forces in the porous membrane extraction include temperature, concentration, pressure, heat flux, volume flux, momentum flux and electrical flux. The selectivity in the extraction process is governed mainly by the membrane properties, as well as the physical-chemical properties that exist between the membrane and the permeate components. Dialysis and electrodialysis are among the examples of porous membrane extraction techniques (Chimuka et al., 2004).

\section{Non-porous liquid membrane techniques}

Non-porous membranes do not have pores as the name suggest, therefore analytes movement in these setups is controlled mostly by diffusion. In the non-porous membrane systems, liquids are held in the pores of polymeric membranes to form what may either be called, two-phase or three phase supported liquid membrane extraction. Different configurations of non-porous membrane extractions are known to exist such as supported liquid membrane extraction (SLM) technique, micro-porous mem-

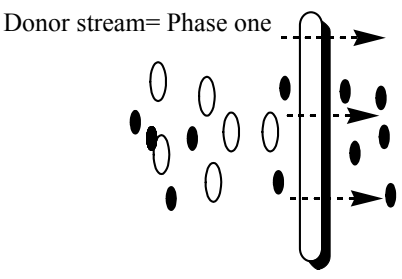

Permeate stream $=$ phase two

Figure 1

Porous membrane extraction process. The arrows show the direction of the movement of the different molecules under a concentration gradient. 


organic phase
held by
capillari force

Figure 2

Schematic representation of the extraction of basic organic compounds by SLM technique. Acidic compounds cannot be extracted, and the neutral species can only transfer by diffusion, without enrichment. Equivalent chemistry is implemented for extraction of organic acids.

(a)

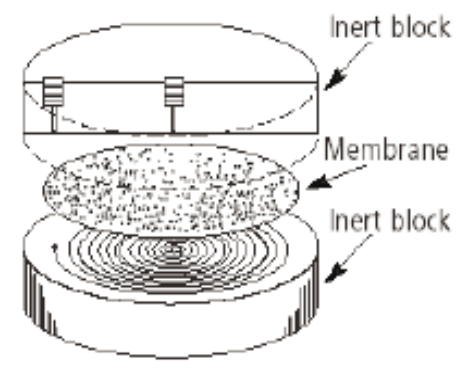

(b)

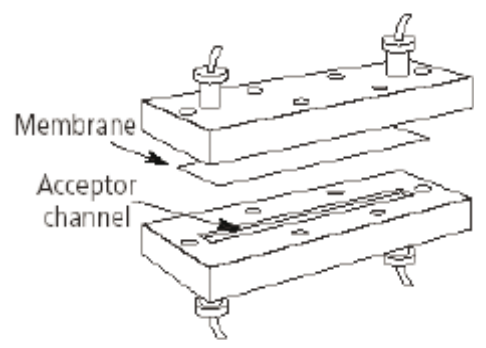

Figure 3

SLM technique performed in film/flat sheets:

(a) is a $1 \mathrm{ml}$ channel and (b) is a $10 \mu \ell$ channel

brane liquid-liquid extraction (MMLLE) technique, emulsion liquid membranes (ELM) and stabilised liquid membrane device (SLMD) extraction techniques.

\section{Supported liquid membrane extraction (SLM) technique}

Supported liquid membrane (SLM) is a three-phase system in which an organic phase is sandwiched (interposed) between two aqueous phases (Figs. 2, 3a and 3b). This liquid is immobilised in the pores of a supporting porous material and is held by the capillary action. One of the two aqueous phases is actually the test or sample solution containing the analyte of interest, while the other one forms the stripping solution to accept the extracted analyte (stripping/acceptor solution). In the SLM technique, the volumes of the stagnant strip solutions that are used are normally much smaller than the sample solution volumes pumped through and this ensures high preconcentration factors. Therefore, with the SLM technique, sample cleanup and enrichment can be achieved simultaneously (Jönsson, 1992; 1993; 1999; Chimuka et al., 1998).
SLM extraction technique is suitable for polar and ionic compounds such as organic acids, bases and metals. In the extraction of basic or acidic analytes, the $\mathrm{pH}$ of the donor solution must be such that the compounds are in their neutral or uncharged forms, thus allowing them to enter the membrane. The $\mathrm{pH}$ of the acceptor is maintained such that once in the membrane, the analytes are extracted into the acceptor in a charged form and cannot be back-extracted into the donor. The $\mathrm{pH}$ gradient therefore provides the driving force (Hylton and Mitra, 2007; Chimuka et al., 1998).

\section{Facilitated transport in liquid membranes}

To enhance the selectivity of the liquid membrane during the extraction of ionising compounds, a suitable carrier molecule with a high affinity for the analytes may be incorporated (Jönsson et al., 1994). Under these conditions, carrier mediated transport involves the reversible complex formation between the carrier and the analyte (Jönsson et al., 1994). For instance, in the extraction of metals, a complexing agent (ligand) stronger than organic carrier is normally incorporated into the strip solution and the metal ion transport from the donor via the hydrophobic membrane to the stripping solution is then driven by either proton gradient or by counter anion/cation (Figs. 4a and b) (Parthasarathy et al., 1997). The mobile carrier in the membrane complexes the metal in the donor side, diffuses across the membrane to the acceptor side where it is exchanged for a proton or taken up by a much stronger carrier (Fig. 4b). Mulugeta and Megersa extracted bipyridilium herbicides from water samples whereby di-(2-ethylhexyl) phosphoric acid was used as a carrier (Mulugeta and Megersa, 2004). Chimuka et al., (2005) have also reported the use of tri-n-butyl phosphate (TBP) as an extractant in the monitoring of uranium in complex matrix samples.

Supported liquid membranes involve the distribution of analyte in three phases to bring about clean-up/separation as well as enrichment of the extract (permeate). There are two main parameters that are of paramount importance to evaluate the performance of the SLM extraction process. These factors are the enrichment factor $\left(E_{p}\right)$ and extraction efficiency $\left(E_{e}\right)$. The

(a)

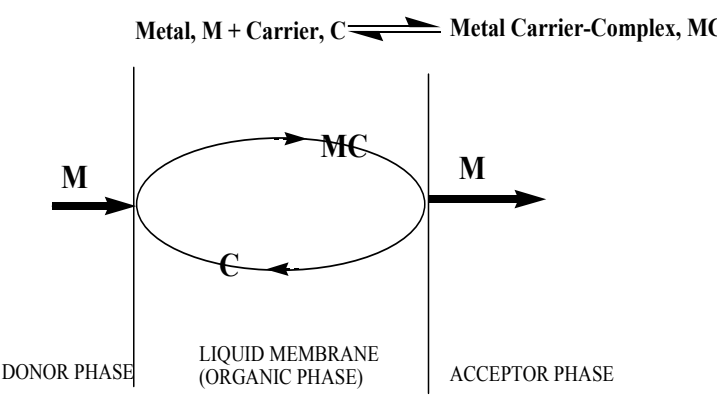

(b)

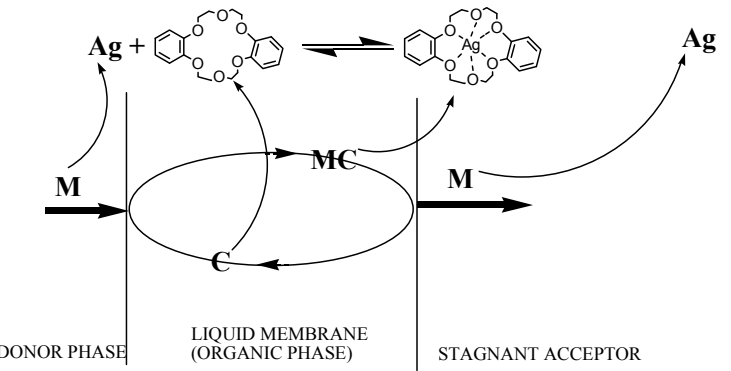

Figure 4

Facilitated transport in liquid membranes: (a) general example; (b) a typical illustration of how complexation may occur. 
enrichment factor $(E)$ refers to a ratio of analyte concentration in the extract in the acceptor phase to that in the donor phase. The mathematical relationships that exist between the concentrations of the analyte in the acceptor and donor phases and the extraction efficiency are given by the following equations:

$$
E_{f}=\frac{C_{a}}{C_{d}}
$$

$C_{\mathrm{a}}$ is the analyte concentration in the acceptor phase

$C_{\mathrm{d}}$ is the analyte concentration in the donor phase

$\mathrm{E}_{\mathrm{f}}$ is the enrichment factor.

On the other hand, the extraction efficiency refers to the fraction of analyte that is extracted into the acceptor phase and is defined mathematically as:

or

$$
E_{e}=\frac{m_{a}}{m_{b}}=\frac{C_{a} V_{a}}{C_{d} V_{d}}
$$

$$
E_{e}=E_{f} \frac{V_{a}}{V_{d}}
$$

where:

$m_{\mathrm{a}}=$ mass of analyte in the acceptor phase

$m_{\mathrm{d}}=$ mass of the analyte in donor phase

$V_{\mathrm{d}}$ and $V_{\mathrm{a}}$ are the volumes of the donor and acceptor respectively.

Supported liquid membranes have been used mostly in the extraction of ionisable pollutants in water and wastewater samples. This technique has been used extensively in the extraction of agrochemical residues in natural waters (Chimuka et al., 1997; Megersa and Jönsson, 1998), environmental and biological samples (Megersa et al., 2001) and in fruit juices (Khrolenko et al, 2002, 2005). Supported liquid membrane application in the extractions of metals in waters is well documented and has shown great success which is evidenced by numerous reports covering a wide range of metals (Smith, 1997; Djane et al., 1997a; 1997b; 1998; 1999; Papantoni et al., 1995; Soko et al., 2003; Romero and Jönsson 2005; Valenzuela et al., 2007).

\section{Micro-porous membrane liquid-liquid extraction (MMLLE) technique}

Unlike in the SLM technique which is a three-phase system, MMLLE technique is a two-phase system whereby analytes are extracted from an aqueous solution into an organic phase (Fig. 5).

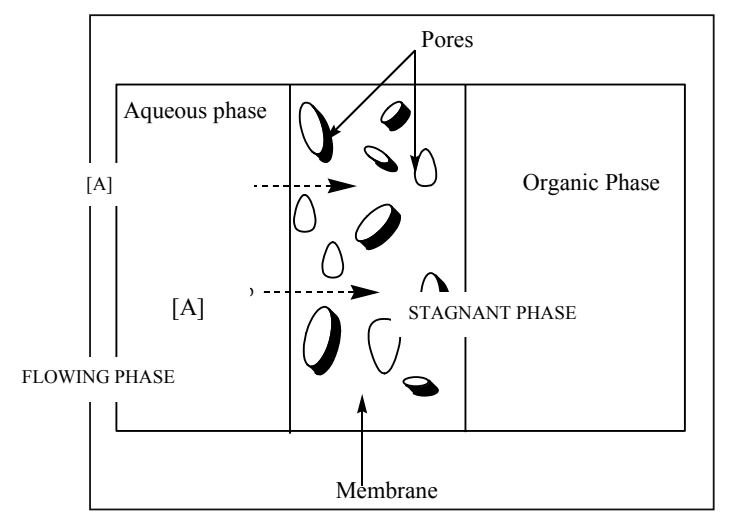

Figure 5

Schematic diagram of MMLLE schematic showing how analytes diffuse across a micro-porous membrane
The performance of the MMLLE technique is to a large extent dependent on partition coefficient, $K_{\mathrm{p}}$ such that:

$$
\mathrm{K}_{\mathrm{p}}=\frac{\mathrm{C}_{\mathrm{o}}}{\mathrm{C}_{\mathrm{a}}}
$$

where:

$C_{\mathrm{o}}$ and $C_{\mathrm{a}}$ represent the equilibrium analyte concentration in the organic and aqueous phases, respectively.

For an analyte to be efficiently extracted with MMLLE, it should have low solubility in the aqueous phase as well as volatility. Non-polar organic compounds and non-ionising compounds usually extract well with high efficiencies and preconcentrate higher than the polar and ionising molecules due to the solubility factors. In MMLLE, the migration of molecules from aqueous to organic phase is driven by the concentration gradient of the analyte and is limited by its partition coefficient.

MMLLE has been reported in the extraction of environmental pollutants such as the extraction of dinitrophenolic compounds [Bartolome et al., 2007], isobutylicetophenone (Zorita et al., 2007), organo tin compounds (Cukrowska et al., 2004), and organo lead compounds (Cukrowska et al., 2007) from aqueous samples.

\section{Hollow fibre micro-extraction technique}

The hollow fibre micro-extraction technique is also known as liquid phase micro-extraction (LPME). In this technique a porous polypropylene hollow fibre strand is used and to it a very small volume of acceptor solution (in micro-litre ranges) is filled. The filled hollow fibre is then exposed to an organic liquid to impregnate the pores and then placed in an aqueous sample where extraction will proceed. Liquid phase microextraction can be carried out in either a two phase (MMLLE) or a three phase (SLM) depending on the analyte being extracted. The application of LPME has been reported in a wide variety of analyses of environmental pollutants such as the PAHs, drugs and pesticides (Hou et al., 2003; Hou and Lee 2002; Ma et al., 2006, Dziarkowska, 2007).

There are two modes of LPME that have been reported thus far and these include the static LPME and dynamic LPME (Figs. 6a and b) (Zhao and Lee, 2002). In static mode, the acceptor solution remains in the lumen throughout the entire extraction. In dynamic mode, however, the acceptor is repeatedly introduced and withdrawn from the lumen. Some researchers

(a)

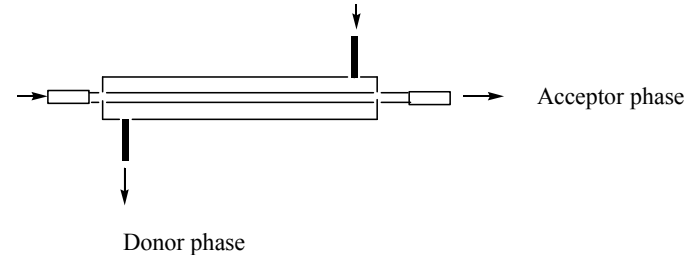

(b)

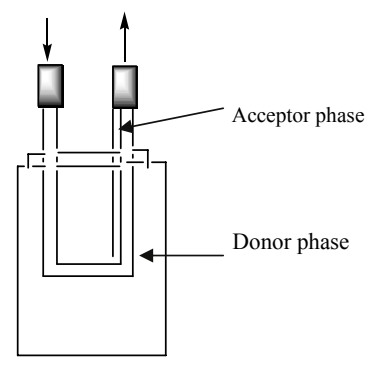

Figure 6

Hollow fibre configurations; $a=$ dynamic mode; $b=$ static mode 
have indicated that the dynamic mode has an edge over the static mode in that it can result in much higher enrichment factors (Hou et al., 2003; Hou and Lee, 2002; Basheer et al., 2003).

An example of the application of HFSLM static mode was reported by Kou et al. (2004) in the analysis of haloacetic acids in water, where they analysed 9 haloacetic acids to sub $\mu \mathrm{g} \cdot \ell^{-1}$ detection limits, low RSD values between 1.5 to $10.8 \%$ and high enrichment factors ranging between 300 to 3000 . Nora-adisak and Varanusupakul (2006) have also reported the use of a similar configuration to determine trihalomethanes in water samples.

\section{Emulsion liquid membrane (ELM) technique}

The emulsion liquid membrane (ELM) (Fig. 7) is designed to have a large surface area per unit sample volume, which gives it an advantage of high flux rates across the membrane as well as high preconcentration factors. ELM technique has several disadvantages, all related to the formation of emulsion and these are:

- Controlling the factors that affect emulsion stability such as ionic strength, $\mathrm{pH}$, etc.

- If for any reason, the membrane does not remain intact during use, the separation that has been achieved is destroyed

- In order to recover the receiving phase and also to replenish the carrier phase, one has to break the emulsion. This is a difficult task, since in order to make the emulsion stable; you have to work against the ease of breaking it back down.

Despite the above cited drawbacks, several applications of ELMs have been reported both for speciation of metal ions (Kumbasar and Tutkun, 2001; Gasser et al., 2007; Fonad and Bart 2008; Sengupta et al., 2007; Sabry et al., 2007; Garmeiro et al., 2007) and organic compounds (Lee, 2008; Kaghazch et al., 2006).

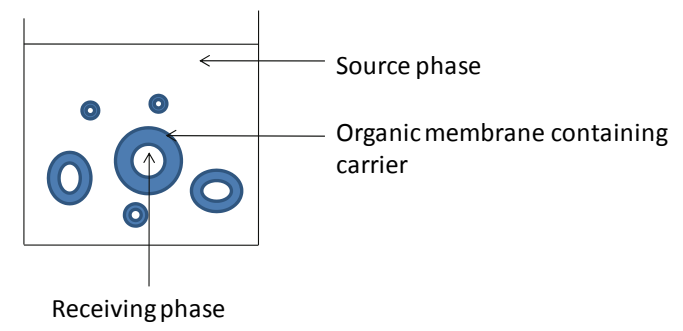

Figure 7

ELM extraction set-up

\section{Conclusions}

Liquid membrane extraction techniques in various forms and configurations have many sample-preparation applications and a potential to be extended to even more different pollutants in the water samples. Depending on the type of analyte and possible extraction process, it is possible to select the most appropriate liquid membrane technique.

\section{References}

AMARA M and KERDJOUDJ H (2007) A modified anion-exchange membrane applied to purification of effluent containing different anions. Pre-treatment before desalination. Desalination 206 205-209.

AROUS O, GHERROU A and KERDJOUDJ H (2004a) Removal of $\mathrm{Ag}(\mathrm{I}), \mathrm{Cu}(\mathrm{II})$ and $\mathrm{Zn}(\mathrm{II})$ ions with a supported liquid membrane containing cryptands as carriers. Desalination 161 295-303.
AROUS O, KERDJOUDJ H and SETA P (2004b) Comparison of carrier-facilitated silver (i) and copper (ii) ions transport mechanisms in a supported liquid membrane and in a plasticized cellulose triacetate membrane. J. Membr. Sci. 241 177-185.

AUDUNSSON GA (1986) Aqueous-aqueous extraction by means of a liquid membrane for sample cleanup and preconcentration of amines in a flow system. Anal. Chem. 58 2714-2723.

BARTOLOME L, LEZAMIZ J, ETXEBARRIA N, ZULOAGA O and JÖNSSON JÅ (2007) Determination of trace levels of dinitrophenolic compounds by microporous membrane liquid-liquid extraction in environmental water samples. J. Sep. Sci. 30 2144-2152.

BASHEER C and LEE HK (2004) Hollow fiber membrane-protected solid-phase microextraction of triazine herbicides in bovine milk and sewage sludge samples. J. Chromatogr. A 1047 189-194.

BASHEER C, BALASUBRAMANIAN R and LEE HK (2003) Determination of organic micropollutants in rainwater using hollow fiber membrane/liquid-phase microextraction combined with gas chromatography-mass spectrometry. J. Chromatogr. A 1016 11-20.

BERHANU T, LIU JF, ROMERO AR, MEGERSA N and JÖNSSON JÅ (2006) Determination of trace levels of dinitrophenolic compounds in environmental water samples using hollow fiber supported liquid membrane extraction and high performance liquid chromatography. J. Chromatogr. A 1103 1-8.

CHAO JB, LIU JF, WEN MJ, LIU JM, CAI YQ, and JIANG GB (2002) Determination of sulfonylurea herbicides by continuous-flow liquid membrane extraction on-line coupled with high-performance liquid chromatography. J. Chromatogr. A 955 183-189.

CHIMUKA L, MEGERSA N, NORBERG J, MATHIASSON L and JONSSON JA (1998) Incomplete trapping in supported-liquid membrane extraction with a stagnant acceptor phase. Anal. Chem. $\mathbf{7 0}$ 3906-3911

CHIMUKA L, CUKROWSKA E and JONSSON JA (2004) Why liquid membrane extraction is an attractive alternative in sample preparation. Pure and Appl. Chem. 76 707-722

CHIMUKA L, CUKROWSKA E, SOKO L and NAICKER K (2003) Supported-liquid membrane extraction as a selective sample-preparation technique for monitoring uranium in complex matrix samples. J. Sep. Sci. 26 601-608.

CHIMUKA L, NINDI MM and JÖNSSON JÅ (1997) Supported liquid membrane enrichment studies of natural water samples applied to liquid chromatographic determination of triazines. Intem. J. Environ. Anal. Chem. 68 429-445.

CUKROWSKA E, NSENGIMANA H and CHIMUKA L (2007) Speciation of alkylead in aqueous samples with application of liquid membrane probe for extraction and preconconcentration. J. Sep. Sci. 30 2754-2759.

CUKROWSKA E, CHIMUKA L, NSENGIMANA H and KWARAMBA V (2004) Application of supported liquid membrane probe for extraction and preconcentration of organotin compounds from environmental water samples. Anal. Chim. Acta 523141-147.

DJANE NK, NDUNGU K, MALCUS F, JOHANSSON G and MATHIASSON L (1997a) Supported liquid membrane enrichment using an organophosphorus extractant for analytical trace metal determination in river waters. Fresenius J. Anal. Chem. 358 822-827.

DJANE NK, BERGDAHL IA, NDUNGU K, SCHUTZ A, JOHANSSON G and MATHIASSON L (1997b) Supported liquid membrane enrichment combined with atomic absorption spectrometry for the determination of lead in urine. Analyst 122 1073-1077.

DJANE NK, NDUNGU K, JOHANSSON C, SARTZ H, TORNSTROM T and MATHIASSON L (1999) Speciation of chromium in natural waters using serially connected supported liquid membranes. Talanta 48 1121-1132.

DJANE NK, ARMALIS S, NDUNGU K, JOHANSSON G and MATHIASSON L (1998) Supported liquid membrane coupled on line to potentiometric stripping analysis at mercury-coated reticulated vitreous carbon electrode for trace metal determination in urine. Analyst 123 393-396.

DRAPALA A, JÖNSSON JÅ and WIECZOREK (2005) Peptides analysis in blood plasma using on line system of supported liquid membrane and high performance liquid chromatography. Anal. Chim. Acta 553 9-14. 
DZIARKOWSKA K, JÖNSSON JA and WIECZOREK PP (2008) Single hollow fiber SLM extraction of polyamines followed by tosyl chloride derivatization and HPLC determination. Anal. Chim. Acta 606 184-193.

DŻYGIEL P and WIECZOREK P (2001) Supported liquid membrane extraction of glyphosate metabolites. J. Sep. Sci. 24 561-566.

EISERT R and PAWLISZYN J (1997) New trends in solid-phase microextraction. Crit. Rev. Anal. Chem. 27 103-135.

FONTAS C, HIDALGO M, SALVADO V and ANTICO E (2005) Selective recovery and preconcentration of mercury with a benzoylthiourea-solid supported liquid membrane system. Anal. Chim. Acta 547 255-261.

GAMEIRO MJF, BENTO P, ISMAEL MRC, REIS MTA and CARVALHO JMR (2007) Extraction of copper from ammoniacal medium by emulsion liquid membranes using LIX 54. J. Membr. Sci. 293 151-160.

FOUAD EA and BART HJ (2008) Emulsion liquid membrane extraction of zinc by hollow fibre contactor. J. Membr. Sci. 307 156-168

GASSER MS, EL-HEFNY NE and DAOUD JA (2008) Extraction of Co (II) from aqueous solution using emulsion liquid membrane. J. Hazard. Mater. 151 610-615.

HO WSW and WANG B (2002) Strontium removal by new alkyl phenylphosphonic acids in supported liquid membranes with strip dispersion. Ind. Eng. Chem. Res. 41 381-388.

HOU L and LEE HK (2002) Application of static and dynamic liquidphase microextraction in the determination of polycyclic aromatic hydrocarbons. J. Chromatogr. A 976 377-385.

HOU L, SHEN G and LEE HK (2003) Automated hollow fiber-protected dynamic liquid-phase microextraction of pesticides for gas chromatography - Mass spectrometric analysis. J. Chromatogr. A 985 107-116.

HYLTON K and MITRA S (2007) Automated, on-line membrane extraction. J. Chromatogr. A 1152 199-214.

JÖNSSON JÅ and MATHIASSON L (1999) Liquid membrane extraction in analytical sample preparation II. Applications. Trends Anal. Chem. 18 325-334.

JÖNSSON JÅ and MATHIASSON L (2000) Membrane extraction techniques in bioanalysis. Chromatographia 52 (Suppl. S) S8 - S11.

JÖNSSON OB, NORDLOF U and NILSSON UL (2003) The XT-Tube extractor: A hollow fiber-based supported liquid membrane extractor for bioanalytical sample preparation. Anal. Chem. 75 3506-3511.

JUANG RS and HUANG IP (2000) Hollow-fiber membrane extraction of copper (II) from aqueous ethylenediaminetetraacetic acid solutions with Aliquat 336. Ind. Eng. Chem. Res. 39 1409-1415.

JUANG RS, CHEN JD and HUAN HC (2000) Dispersion-free membrane extraction: case studies of metal ion and organic acid extraction. J. Membr. Sci. 165 59-73.

JUANG RS, KAO HC and WU WH (2004) Analysis of liquid membrane extraction of binary $\mathrm{Zn}(\mathrm{II})$ and $\mathrm{Cd}(\mathrm{II})$ from chloride media with Aliquat 336 based on thermodynamic equilibrium models. J. Membr. Sci. 228 169-177.

KAGHAZCHI T, KARGARI A, YEGANI R and ZARE A (2006) Emulsion liquid membrane petraction of L-lysine from dilute aqueous solutions by D2EHPA mobile carrier. Desalination 190 161-171.

KHROLENKO M, DZYGIEL P and WIECZOREK P (2002) Combination of supported liquid membrane and solid-phase extraction for sample pretreatment of triazine herbicides in juice prior to capillary electrophoresis determination. J. Chromatogr. A 975 219-227.

KHROLENKO MV and WIECZOREK PP (2005) Determination of glyphosate and its metabolite aminomethylphosphonic acid in fruit juices using supported-liquid membrane preconcentration method with high-performance liquid chromatography and UV detection after derivatization with $p$-toluenesulphonyl chloride. J. Chromatogr. A 1093 111-117.

KUMBASAR RA and TUTKUN O (2008) Separation of cobalt and nickel from acidic solutions by emulsions using alamine 300 (TOA) as mobile carrier. Desalination 224 201-208.

LEE SC (2008) Development of a more efficient emulsion liquid membrane system with dilute polymer solution for extraction of penicillin G. J. Ind. Eng. Chem. 14 207-212.

LINDEGÅRD B, JÖNSSON JÅ and MATHIASSON L (1992) Liquid membrane work-up of blood-plasma samples applied to gas-chroma- tographic determination of aliphatic-amines. J. Chromatogr. 573 191-200.

LUTHJE K, HYOTYLAINEN T and RIEKKOLA ML (2004) On-line coupling of microporous membrane liquid-liquid extraction and gas chromatography in the analysis of organic pollutants in water. Anal. Bioanal. Chem. 378 1991-1998.

MA M, KANG S, ZHAO Q, CHEN B and YAO S, (2006) Liquid-phase microextraction combined with high-performance liquid chromatography for the determination of local anaesthetics in human urine. J. Pharm. Biomed. Anal. 40 128-135.

MAJORS RE (2003) Trends in sample preparation. LC-GC Europe (Feb.) 2-8

MEGERSA N and JÖNSSON JÅ (1998) Trace enrichment and sample preparation of alkylthio-s-triazine herbicides in environmental waters using a supported liquid membrane technique in combination with high-performance liquid chromatography. Analyst $\mathbf{1 2 3}$ 225-231.

MEGERSA N, CHIMUKA L, SOLOMON L and JÖNSSON JÅ (2001) Automated liquid membrane extraction and trace enrichment of triazine herbicides and their metabolites in environmental and biological samples. J. Sep. Sci. 24 567-576.

MITRA S, ZHU N, ZHANG X AND KEBBEKUS B (1996) Continuous monitoring of volatile organic compounds in air emissions using an on-line membrane extraction-microtrap-gas chromatographic system. J. Chromatogr. A 736 165-173.

MITRA S and KEBBEKUS B (1998) Environmental Chemical Analysis. Chapman and Hall/CRC, Boca Raton, Florida.

MSAGATI TAM and NINDI MM (2001) Determination of benzimidazole anthelmintic compounds by supported liquid membrane extraction and liquid chromatography. J. Sep. Sci. 24 606-614.

MSAGATI TAM and NINDI MM (2004a) Multiresidue determination of sulfonamides in a variety of biological matrices by supported liquid membrane with high pressure liquid chromatography-electrospray mass spectrometry detection. Talanta 64 87-100.

MSAGATI TAM and NINDI MM (2004b) The use of supported liquid membranes in the extraction of macrolides in biomatrices. Michrochim. Acta 148 199-214.

MSAGATI TAM AND NINDI MM (2005a) Supported liquid membrane extraction of anabolic androgenic compounds in biological matrices and detection by LC-ESI-MS. S. Afr. J. Chem. 58 67-73.

MSAGATI TAM and NINDI MM (2005B) Application of supported liquid membranes in the multi-residue extraction of aminoglycoside antibiotics in milk and urine. Bull. Chem. Soc. Japan 78 2135-2141.

MSAGATI TAM and NINDI MM (2006) The use of liquid membranes in the multi-residue extraction of stilbenes in a variety of biological matrices and their detection with LC-ES-MS. Ann. di Chim. 96 635-646.

MULUGETA M and MEGERSA N (2004), Carrier-mediated extraction of bipyridilium herbicides across the hydrophobic liquid membrane. Talanta 64 101-108.

NDUNGÙ K, DJANE NK and MATHIASSON L (1998) Determination of trace metal ions by ion-pair chromatography after enrichment using supported liquid membrane. J. Chromatogr. A 826 103-108.

NORA-ADISAK N and VARANUSUPAKUL P (2006) A simple supported liquid hollow fiber membrane microextraction for sample preparation of trihalomethanes in water samples. J. Chromatogr. A 1121 (2) 236-241.

ORTIZ I, SAN ROMAN MF, CORVALAN SM and ELICECHE AM (2003) Modeling and optimization of an emulsion pertraction process for removal and concentration of $\mathrm{Cr}(\mathrm{VI})$. Ind. Eng. Chem. Res. 42 5891-5899.

PÁLMARSDÓTTIR S, MATHIASSON L, JÖNSSON JÅ and EDHOLM LE (1997) Determination of a basic drug, bambuterol, in human plasma by capillary electrophoresis using double stacking for large volume injection and supported liquid membranes for sample pretreatment. J. Chromatogr. $\mathbf{6 8 8}$ 127-134.

PAPANTONI M, DJANE NK, NDUNGU K, JÖNSSON JÅ and MATHIASSON L (1995) Trace enrichment of metals using a supported liquid membrane technique. Analyst 120 1471-1477.

PARTHASARATHY N, PELLETIER M and BUFFLE J (1997) Hollow fiber based supported liquid membrane: A novel analytical system 
for trace metal analysis. Anal. Chim. Acta 350 183-195.

PATNAIK P (1997) Handbook of Environmental Analysis - Chemical Pollutants in Air, Water, Soil and Solid Wastes. CRC Press, Boca Raton, Florida.

PAWLISZYN J (2003) Sample preparation: Quo Vadis? Anal. Chem. 75 2543-2558.

QIN Y, SHETH JP and SIRKAR KK (2002) Supported liquid membrane-based pervaporation for VOC removal from water. Ind. Eng. Chem. Res. 41 3413-3428.

ROMERO R and JÖNSSON JÅ (2005) Determination of free copper concentrations in natural waters by using supported liquid membrane extraction under equilibrium conditions. Anal. Bioanal. Chem. 381 1452-1459.

SABRY R, HAFEZ A, KHEDR M and EL-HASSANIN A (2007) Removal of lead by an emulsion liquid membrane: Part 1. Desalination 212 165-175.

SANDAHL M, JÖNSSON JÅ and MATHIASSON L (2002) On-line automated sample preparation for liquid chromatography using parallel supported liquid membrane extraction and microporous membrane liquid-liquid extraction. J. Chromatogr. A 975 211-217.

SANDAHL M, MATHIASSON L and JÖNSSON JÅ (2000) Determination of thiophanate-methyl and its metabolites at trace level in spiked natural water using the supported liquid membrane extraction and the microporous membrane liquid-liquid extraction techniques combined on-line with high-performance liquid chromatography. J. Chromatogr. A 893 123-131.

SHEN Y, GRONBERG L and JÖNSSON JÅ (1994) Experimental studies on the enrichment of carboxylic-acids with tri-n-octylphosphine oxide as extractant in a supported liquid membrane. Anal. Chim. Acta 292 31-39.
SENGUPTA B, BHAKHAR MS and SENGUPTA R (2007) Extraction of copper from ammoniacal solution into emulsion liquid membrane using LIX 84 ®. Hydrometallurgy 89 311-318.

SMITH JJ (1997) The Extraction of Nickel with the Use of Supported Liquid Membrane (SLM). WRC Report No. 617/1/97. Water Research Commission, Pretoria, South Africa.

SMITH WF (2004) Foundations of Materials Science and Engineering ( $3^{\text {rd }}$ edn.) McGraw-Hill, New York, USA.

TADEO JL, SÁNCHEZ-BRUNETE C, ALBERO B and LORENA GONZÁLEZ (2004) Analysis of pesticide residues in juice and beverages, Critical Rev. Anal. Chem. 34 165-175.

VALENZUELA F, CABRERA J, BASUALTO C and SAPAG J (2007) Separation of zinc ions from an acidic mine drainage using a stirred transfer cell-type emulsion liquid membrane contactor. Sep. Sci. Technol. 42 363-377.

VAN DE VOORDE I, PINOY L and DE KETELAERE RF (2004) Recovery of nickel ions by supported liquid membrane (SLM) extraction. J. Membr. Sci. 234 11-21.

YANG C and CUSSLER EL (2000) Reaction dependent extraction of copper and nickel using hollow fibers. J. Membr. Sci. 166 229-238.

YANG MJ, HARMS S, LUO YZ and PAWLISZYN J (1994) Membrane extraction with a sorbent interface for capillary gas-chromatography. Anal. Chem. 66 1339-1346.

ZHAO L and LEE HK (2002) Liquid-phase microextraction combined with hollow fiber as a sample preparation technique prior to gas chromatography mass spectrometry. Anal. Chem. 74 2486-2492.

ZORITA S, BARRI T and MATHIASSON L (2007) A novel hollowfibre microporous membrane liquid-liquid extraction for determination of free 4-isobutylacetophenone concentration at ultra trace level in environmental aqueous samples. J. Chromatogr. A 1157 30-37. 
